\title{
ECOS DO MODERNISMO E DE MÁRIO DE SÁ-CARNEIRO NA REVISTA $O$ OCIDENTE (1878-1914)
}

Fernanda Suely Müller ${ }^{1}$

RESUMO: Tendo como fio condutor as matérias de/sobre o escritor Mário de Sá-Carneiro inseridas na revista $O$ Ocidente (1878-1914), discutiremos a divulgação do Modernismo promovido pelo periódico e procuraremos ainda delinear qual leitura e recepção que o veículo elabora sobre essa nova estética poética.

PALAVRAS-CHAVE: Mário de Sá-Carneiro; revista $O$ Ocidente; Modernismo português; imprensa periódica literária.

ABSTRACT: Having as main theme the articles from/about the writer Mário de Sá-Carneiro that have been published at $O$ Ocidente magazine (1878-1914), we want debate the Modernism's divulgation realized by this review. We are looking for to delineate also what was the magazine's interpretation about that new poetics aesthetics.

KEYWORDS: Mário de Sá-Carneiro; O Ocidente magazine; portuguese Modernism; literary periodic press.

Figura central da gênese do movimento modernista português, Mário de SáCarneiro (1890-1916), ao lado do amigo Fernando Pessoa, deixou um legado inestimável de sentimentos, experiências e sensações às letras portuguesas traduzidas em sua ampla obra poética, novelas e até mesmo através da belíssima correspondência que estabeleceu com o autor de Mensagem.

Nascido em Lisboa aos 19 de Maio de 1890, foi filho único de Águeda Maria de Sousa Peres Murinello de Sá-Carneiro e do Engenheiro Carlos Augusto de Sá-Carneiro. Aos dois anos de idade ficou órfão de mãe. Em 1902 começou a escrever poesia. Matriculou-se na Faculdade de Direito de Coimbra em 1911, mas não chegou a concluir o ano.

Em 1912 conheceu Fernando Pessoa e partiu para Paris. Na capital francesa dedicou-se sobretudo à vida de boémia dos cafés e salas de espetáculo, onde conviveu com Santa-Rita Pintor. Publicou em fins de 1913 (com data do ano seguinte), $A$

\footnotetext{
${ }^{1}$ Doutoranda do Programa de Pós-Graduação em Literatura Portuguesa da Universidade de São Paulo (USP) e bolsista da Fundação de Amparo à Pesquisa do Estado de São Paulo (FAPESP)
} 
Confissão de Lúcio (novela) e Dispersão (poesia) e intensifica sua correspondência com Fernando Pessoa a quem envia seus poemas.

Em abril de 1915, em Lisboa, editou a revista Orpheu juntamente com os modernistas Almada Negreiros e Fernando Pessoa. A Geração de Orpheu, como então ficou conhecida, reunia-se com frequência em cafés da baixa lisboeta. Além dos já citados, integravam também o grupo Amadeo de Sousa Cardoso, Almada Negreiros, Raul Leal, Luis de Montalvor, Armando Côrtes Rodrigues bem como Antônio Ferro. Destinada a congregar as diversas tendências estéticas destes artistas e a intervir na vida intelectual e literária portuguesa, esta revista, pelo seu caráter inovador, destacou-se como uma fundamental e necessária injeção de novos ares noliterário português.

Esse novo projeto literário foi muito bem-recebido pelo público-alvo intelectualizado mas, entretanto, no público em geral causou grande escândalo e polêmica. O número um e dois da revista Orpheu foram financiados pelo pai de Mário de Sá-Carneiro e, estando já para edição o número três da revista, suspende o financiamento deixando o filho em desespero.

Personalidade corroída pela neurose levada ao extremo e de uma sensibilidade multifacetada, Sá-Carneiro foi essencialmente um esteta que nunca vira a sua atividade literária como um instrumento ou sequer uma profissão, mas sim como um ideal que sempre procurou e colocou acima de tudo. Como poeta autêntico que foi encarnou, como ninguém, as frustrações e os pesadelos da sua terra, dividida entre a nostalgia da glória e do luxo e a atração pela modernidade europeia. Tudo nele foi angústia pessoal, desencanto e filtração de angústias coletivas, reflexos peculiares da cultura da sociedade moderna do qual foi típico representante.

A sua obra foi talvez, ela mesma, o mito que alimentou a vida de Sá-Carneiro e que ditou a sua morte no momento exato em que as últimas saídas visíveis se fecharam à sua frente. Nas suas cartas a Fernando Pessoa transmite a ritmo crescente os seus problemas e o seu desespero. Demonstrando uma coerência extraordinária Sá-Carneiro numa coragem impetuosa, numa solidão extrema, confronta-se com a morte prematura e inexorável suicidando-se em 26 de Abril de 1916. Teve as seguintes obras editadas: Amizade (teatro, juntamente com Thomaz Cabreira Júnior, em 1912); Princípio (novelas, 1912); Dispersão (poemas, 1914); A Confissão de Lúcio (novela, 1914); Céu 
em Fogo (contos, 1915); Indícios de Oiro (poemas, 1937); Cartas a Fernando Pessoa (dois volumes, 1958-1959).

A imprensa periódica em geral e, sobretudo, as revistas de cultura, letras e belas artes em Portugal sempre desempenharam um papel fundamental na difusão das novas correntes literárias desde o século XIX, pelo menos (lembremo-nos da revista Panorama, de Alexandre Herculano, por excelência porta-voz Romantismo no país, por exemplo).

Particularmente em relação ao movimento literária modernista, verifica-se um estreitamento dessa relação entre a imprensa e as letras portuguesas, sobretudo porque o lançamento da revista Orpheu delimita o próprio marco histórico inicial do Modernismo português.

Se é certo, portanto, que a revista Orpheu inaugurou oficialmente esse novo pensamento estético-filosófico moderno nas terras de além-mar, principalmente através dos manifestos, prosa e poesia ali veiculados, também é certo porém que não foi a primeira revista literária portuguesa a publicar e a divulgar a obra de escritores ditos modernos como Mário de Sá-Carneiro.

Como vimos anteriormente, consta na fortuna crítica sá-carneiriana que o volume de poemas Dispersão, por exemplo, foi publicado em Lisboa em 1914 mas, segundo Maria Aliete Gallhoz, de

junho de 1913 a dezembro de 1913, [o autor, em Lisboa] [...], prepara as edições de $A$ confissão de Lúcio e Dispersão, que trazem as datas de 1914 mas estavam nas mãos da imprensa desde os princípios de dezembro de 1913. "A capital", de 11 de dezembro já se lhe refere. (GALHOZ, 1963, p.16).

De fato, outro orgão de relevo da imprensa lusitana que comentou e divulgou as obras de Mário de Sá-Carneiro antes que as mesmas tivessem sequer saído do prelo foi a revista $O$ Ocidente (1878-1914) que, já na edição de 20 de dezembro de 1913 (número 1259) publica, na seção "Crônica Ocidental”, uma interessante crítica sobre o conjunto da obra sá-carneiriana - anunciando, inclusive, o lançamento das obras supra-citadas para o então próximo ano de 1914 - e, na edição de 10 de janeiro de 1914 (número 1261), veicula o poema“Salomé”, integrante do volume póstumo Indícios de Oiro (1937). Posteriormente, na edição de 10 de fevereiro de 1914 (número 1264), publica também um poema de Antônio Ferro, outro importante expoente do Modernismo 
português, intitulado "A catedral”, com a dedicatória a Mário de Sá-Carneiro e sobre o qual falaremos mais adiante.

O periódico O Ocidente: Revista Ilustrada de Portugal e do Estrangeiro foi publicada entre 1878 e 1914, com sede em Lisboa, ao ritmo de três números mensais (saía sempre nos dias 10, 20 e 30 de cada mês com exceção, é claro, de fevereiro, quando o número saía sempre no dia 28 ou 29) e somou uma incrível marca de 1296 números publicados ao longo dos seus 37 anos de vida. Tal longevidade, muito incomum na imprensa periódica da época, atesta o sucesso deste projeto editorial planejado principalmente por Caetano Alberto da Silva, gravador e principal capitalista da empresa Ocidente e por Manuel de Macedo, desenhista ilustrador, os seus grandes dinamizadores.

Contudo, a edição de publicações periódicas ilustradas em Portugal já não era uma novidade. $\mathrm{O}$ que marcou a diferença foi que $O$ Ocidente fez escola e foi escola de gravadores. De fato, o projeto alicerçou-se na criação de um atelier de formação de gravadores, porque com os que então existiam não era possível assegurar a atualidade imagética que se pretendia imprimir à publicação, nem tão pouco a reprodução de obras de arte nacionais, as recreações históricas, etc., que faziam parte do seu programa. Contratá-los no estrangeiro estava fora de questão, pois $O$ Ocidente fazia questão de ser, tanto quanto possível, um produto $100 \%$ nacional; destarte montou-se, portanto, o atelier de gravura na Rua do Loreto, em Lisboa, sob a direção do mestre Caetano Alberto.

O Ocidente foi uma revista muito diversificada no tocante aos conteúdos, pois no seu horizonte estava sempre um amplo espectro de públicos em matéria de interesses, e publicava matérias tanto para o gosto masculino quanto para o feminino (mas sem se restingir, no entanto, aos assuntos clássicos, como a moda ou os trabalhos domésticos). Pelo contrário, a mulher idealizada pela revista $O$ Ocidente seria moderna, intelectual, interessada na vida social das altas personalidades, nas artes, na literatura, na história, quem sabe por algumas curiosidades científicas e suas aplicações práticas, marcando a marcha do progresso civilizacional (mas menos por política, é evidente, embora a revista reconhecesse que alguns aspectos tão combatidos por eles em seus artigos sobre a então atual sociedade portuguesa como o problema da educação e do analfabetismo, por exemplo, só seriam resolvidos de forma efetiva e eficaz caso 
houvesse um maior interesse e engajamento feminino em prol do desenvolvimento da nação portuguesa).

Ao que tange a política - via de regra -, além da coluna de "João Verdades", o tema conquistou espaço na famosa Crônica Ocidental, geralmente assinada pelos diretores literários que a revista conheceu ao longo dos seus 36 anos de vida: Guilherme de Azevedo (1878 a 1880), Gervásio Lobato (setembro de 1880 a junho de 1895 , quando falece), João da Câmara (1895 a Dezembro de 1907, quando falece), Alfredo Mesquita, que a partir do n. ${ }^{o}$ 1048, assume o pseudônimo de João Prudêncio (Jan.1908 a Dez. 1912) e Antônio Cobeira (1913 a 1914). Esporadicamente, Caetano Alberto, o diretor e proprietário, também vertia a sua prosa na Crônica Ocidental.

A revista $O$ Ocidente foi contemporânea a um período prolífero em mudanças, no país e no mundo e em suas páginas se via refletido esse novo espírito moderno. As idéias corriam agora velozes por telégrafos, telefones, e os homens circulavam a velocidades impensáveis por carris, sobre rodas e até já iam conquistando inclusive o ar. Novas formas de produção de riqueza concorriam com modelos tradicionais, impondo outros equilíbrios, quer entre os homens, quer entre as nações. Em Portugal a Monarquia Constitucional deu lugar à República, enquanto em outros cantos da velha Europa a revolução preparava-se em nome de uma sociedade socialista. Do outro lado do Atlântico, projetava-se a sombra cada vez maior dos Estados Unidos da América. E a África nesse contexto surgia, mais do que nunca, como um enorme tabuleiro onde todos queriam lançar cartas. Até as leitoras eram então incentivadas a dar um contributo mais direto para a mudança que assolava o mundo, por via de uma série de textos sobre a luta das sufragistas inglesas, publicados a partir de 1912 quando também, não por acaso, a emancipação da mulher se tornaria um tema recorrente nas páginas da revista.

Todo este "admirável e assustador mundo novo" emergente desfilava em Ocidente, através da combinação inteligente da imagem e da palavra. A revista não deixava de privilegiar também, no final das oito páginas correntes de cada edição, um espaço para a publicação da filigrana dos dias - as novidades editoriais, os espetáculos, a necrologia, a meteorologia e outras miudezas.

Ao que concerne o âmbito mais lato das idéias, e seguindo o mesmo critério da dimensão e continuidade dos textos, destacaram-se as reflexões que D. Francisco de Noronha desenvolveu, a partir de 1900, sobre temas como, a origem do socialismo, a 
escravatura, a miséria, a propriedade, o trabalho, a família e o mundo infantil, publicadas sob o título Questões Sociais. Evocou-se ainda o nome de alguns dos colaboradores mais regulares da revista, sobretudo após 1902, já que para o período anterior há informação detalhada na já referida edição que assinala o seu $25 .^{\circ}$ aniversário. Entre muitos outros, redigiram textos para $O$ Ocidente os seguintes autores: Ruy de Aboim, Brito Aranha, Ribeiro Arthur, Maximiliano de Azevedo, Vilhena Barbosa, Mário Brandão, Nogueira de Brito, Júlio de Castilho, Luiz Chaves, J. Ribeiro Christino, Victor Moraes Júdice da Costa, Manuel da Granja, Henrique Marques Júnior, Almada de Lacerda, M. Cardoso Martha, Fernando Mendes, Henrique Lopes Mendonça, A. de Mello e Niza, Damasceno Nunes, Ramalho Ortigão, Antônio Corrêa D’Oliveira, J. A. Macedo de Oliveira, Esteves Pereira, Alfredo Pinto, Dr. Cortez Pinto, Pedro Pinto, Teixeira de Queiroz, Hippolyto Raposo, Brito Rebello, Francisco Serra, Ricardo Souza, Alberto Telles.

Não há informação quanto à sua tiragem, mas não seria superior a 1000 exemplares e a sua longa vida dependeu, em grande medida, da vontade e do esforço dos homens que se envolveram neste projeto editorial. Quando O Ocidente completou o seu 25. aniversário, ainda mantinha algumas dezenas dos seus primeiros assinantes, fato que refere com orgulho, revelando-lhes a identidade através de uma artigo publicado em tal ocasião pela revista. Para a sua distribuição a empresa Ocidente contava, no caso dos assinantes, com os serviços de correio, e para as vendas avulso com uma rede de agentes presente em "todas as capitais de Distrito do continente, Ilhas, Possessões Ultramarinas, em Berlim, Manchester, Paris, Leipzig, Madrid e em diferentes estados da Índia, Brasil, Califórnia, Japão, etc.” Em relação ao preços de lançamento, a revista conheceu apenas uma atualização, em 1881, o que era mais um sinal do grau de envolvimento pessoal dos elementos da equipe dirigente e, possivelmente, até de alguns colaboradores. De qualquer forma, é notório que a empresa Ocidente tivesse procurado outras fontes de rendimento, como a edição de suplementos temáticos, sobretudo gravuras, a partir de 1880, e do Almanach Ilustrado do Ocidente, a partir de 1887 e, posteriormente, a venda de espaço publicitário que ocorreria apenas em 1902.

A propósito de Mário de Sá-Carneiro e sua obra, escreve Antônio Cobeira, na Crônica Ocidental do número 1259 de 20 de dezembro de 1913: 
Mário de Sá-Carneiro não é nome desconhecido, em absoluto, no meio pequenino da nossa literatura atual. Contos dispersos, narrativas vagabundas - gritam, de sul a norte, a sua individualidade. Barros amassados em alma, estatuetas fumegantes de febre, flores entonteadas de desvarios, águias famintas de sol, hipógrifos sedentos de infinito - as figuras que a sua literatura de requinte sabe evocar, persistem, possessas e obsessas, no círculo fluído da nossa imaginação.

Já no - Princípio - primeira obra da sua predileção, surgem tipos, grifados de estranheza, tatuados de doença, cambaleantes num desiquilíbrio de época e novidades, opiados de sonho; somente, nos seus livros recém-publicados, requintam no requinte e estilizam-se de realidade em espelhos côncavos de magia.

A Confissão de Lúcio - narrativa - e Dispersão - florilégio de doze poesias - tais são os títulos das obras recentes de Mário de SáCarneiro. [...]

Evidentemente, na - Confissão de Lúcio - a intriga romanesca nada importa. Os incidentes episódicos nada valem. Se cuidarem de coincidir as arestas da novela no quadro estrito da realidade, as dúvidas surgem e importunam... O entrecho é o esqueleto que se reveste as roupagens belas e roçagantes.

A narrativa torna-se eminentemente notável, pelo símbolo que reanima, intenção psicológica e esboço estilizado de atitudes.

As personalidades que ali vivem - não se agitam, é certo, no mundo da realidade, amurado e sáfaro, porque dele, de propósito e obstinação, fugiram sempre. As suas vidas - são projeções de vidas. Os seus mundos - são além-mundos. As suas realidades são superrealidades. As suas ações são esbatidos de fatos.

A - Dispersão - é a tragédia dolorosíssima duma alma que se perdeu a si própria, nos meandros do seu labirinto profundo, e tenta objetivar-se em realidade e sonho na sombra remotíssima que a sua luz interior projeta no infinito. A vida procura uma realidade. $\mathrm{O}$ esforço procura um ponto de referência. A alma vaga sobre ruínas quanto mais sobe, mais desce, quanto mais se busca, e anciosamente e desvairadamente, mais ela se perde, alheada, sonâmbula, aniquilada. De onde a onde, surge e traz nos olhos, em febre e deslumbro, a visão de maravilhas perdidas irremediavelmente...

Mário de Sá-Carneiro imprimiu com suntuosidade e carinho esta obra pequenina e querida. José Pacheco desenhou a capa, alegórica, perturbante, magnífica - aerisada de sonho, iluminada de magoa, tocada de graça, atrozmente pungida de tristeza.

Milagres, ruínas, pesadelos, forcas de luz, torres altas de marfim... (COBEIRA, 1913, p.1 e 2).

Como podemos depreender pela crítica que dirige à obra de Mário de SáCarneiro neste artigo, Cobeira comenta com propriedade as características dessa nova estética moderna e não o fez certamente por acaso. Embora atualmente desconhecido, o 
escritor-jornalista Antônio Cobeira (1892-1959) foi, segundo Urbano Tavares Rodrigues,

com Afonso Duarte e outros, um dos poetas tangenciais à tendência saudosista-nacionalista da Águia. Nesta revista colaborou episodicamente, e por empenhada intercessão de Fernando Pessoa junto de Álvaro Pinto, a quem, depois de Elegia da Alma (1912), talvez, por sinal, a primeira poesia dedicada ao poeta então "renascente", este recomendara a "Romaria das árvores", considerando-a um "poema magnífico" [...] Quando jovem, em Lisboa, os poetas de Orpheu (Pessoa, Sá-Carneiro, CôrtesRodrigues...) tinham-no como um dos seus, não tendo embora colaborado na revista.

(RODRIGUES apud LISBOA, 1994, p.436).

Licenciado em Filologia Românica pelo Curso Superior de Letras, foi condiscípulo de Armando Côrtes-Rodrigues e Hernâni Cidade, lecionou durante alguns anos em Lisboa mas se estabeleceu profissionalmente no Porto como professor do Liceu de Alexandre Herculano. Além da revista O Ocidente, colaborou na Lusíada - Revista Ilustrada de Cultura e, ainda em relação aos modernistas, publicou em prosa a página de memórias "Fernando Pessoa, vulgo 'o Pessoa', e a sua ironia transcendente" no suplemento literário do Comércio do Porto muito posteriormente em 1958.

Mário de Sá-Carneiro aparece novamente nas páginas da revista nas edições de 10 de janeiro de 1914 (número 1261) e de 10 de fevereiro de 1914 (número 1264). Na primeira, veiculada em janeiro de 1914, temos a publicação do poema "Salomé,", que

\section{${ }^{2}$ Salomé}

\section{A Antônio Cobeira}

Insónia roxa. A luz a virgular-se em medo, Luz morta de luar, mais Alma do que lua... Ela dança, ela range. A carne, álcool de nua, Alastra-se para mim num espasmo de segredo...

Tudo é capricho ao seu redor, em sombras fátuas... $\mathrm{O}$ aroma endoideceu, upou-se em cor, quebrou... Tenho frio... Alabastro! A minha'alma parou... E o seu corpo resvala a projectar estátuas...

Ela chama-me em Íris. Nimba-se a perder-me, Golfa-me os seios nus, ecoa-me em quebranto... Timbres, elmos, punhais... A doida quer morrer-me:

Mordoura-se a chorar - há sexos no seu pranto... Ergo-me em som, oscilo, e parto, e vou arder-me $\mathrm{Na}$ boca imperial que humanizou um Santo... 
integra o volume póstumo Indícios de Oiro (1937), porém com duas particularidades: o poema é dedicado ao já mencionado Antônio Cobeira e sub-datado como "Lisboa, 03 de novembro de 1913".

Na edição de 10 de fevereiro de 1914 (número 1264) o nome de Mário de SáCarneiro é citado mais uma vez mas, entretanto, é ele o homenageado. Ná página 4 do citado exemplar, temos a transcrição do poema "A Catedral"3, de Antônio Ferro, dedicado ao poeta e consta como subdatada o dia 20 de dezembro de 1913.

Como sabemos, Antônio Joaquim Tavares Ferro (1895-1956) foi outro grande nome do Modernismo português, também integrante da chamada Geração de Orpheu e que, mais tarde, suscitou grandes polêmicas por seu orientamento político e pelo apoio incondicional que deu à Salazar. Jornalista, ficcionista, cronista, político, Antônio Ferro foi, com apenas 20 anos, o editor da revista Orpheu. Ligado aos elementos do primeiro modernismo, Antônio Ferro, por alguns dos textos então publicados, apresenta-se como um dos mais eloquentes e estridentes porta-vozes daquele movimento artístico. Não tendo completado o curso de Direito, que trocou pelas letras e pelo jornalismo, o autor de Leviana teve uma existência movimentada. Esteve muito novo ainda, dois anos em Angola, de que regressou em 1919, para voltar ao jornalismo, colaborando com $O$ Jornal, O Século, Diário de Lisboa, Diário de Notícias e com a revista Ilustração Portuguesa, da qual foi também diretor. Fora de Portugal se destaca no meio

Lisboa, 3 novembro 1913.

${ }^{3}$ A Catedral

Ao Mário de Sá-Carneiro

O sol vai orquestrando os góticos vitrais,

As rosas do jardim, a luz do meu amor...

Eu ouço o teu olhar e escuto os teus sinais,

Eu nos meus olhos ouço, em melodia, a cor...

Reza agora no poente a catedral imensa

Erguendo para o céu em santo misticismo

As maceradas mãos. A Natureza pensa...

Entro na catedral, ergo-me em Deus e cismo...

Calaram-se os vitrais. O sol onipotente -

A cabeça ideal do pálido Jesus

Que do corpo a cortou só para nos dar luz-

Na bacia do mar tombou pesadamente!...

Vou-me descer de Deus... A noite agora é calma...

A catedral morreu... Eu só lhe vejo a Alma!

20-12-1913 
jornalístico e entrevista figuras de alto gabarito internacional: D'Annunzio, Pio XI, Mussolini, Clémenceau, Maurras, Afonso XIII, Primo de Rivera, Poincaré, etc. Jornalista de forte personalidade e de grande vivacidade como prosador, Antônio Ferro publica no Diário de Notícias, em 1932, as hoje célebres cinco entrevistas com Salazar, que rendido ao seu talento lhe confia, no ano seguinte, a criação do Secretariado da Propaganda Nacional. Nesse cargo, Antônio Ferro tentará definir e impor uma "política do espírito", que buscava, por um lado, recuperar como fonte viva o folclore português e, por outro, fazer de algum modo uma pedagogia do moderno em arte. Olhado com suspeição por quase toda a intelectualidade portuguesa de oposição e com desconfiança por uma direita que lhe temia as ousadias, Antônio Ferro teve de abandonar, em 1950, o Secretariado Nacional da Informação (nome que passara a ter, em 1944 o Secretariado da Propaganda Nacional) pelo posto de ministro plenipotenciário em Berna. Em 1954 vai para o Quirinal, também como ministro, sendo o posto, em 1955, elevado à categoria de embaixada. Foi casado com a poetisa Fernanda de Castro e era pai do escritor Antônio Quadros (1923-1993). São livros de Antônio Ferro: As Grandes Trágicas do Silêncio, 1917; Árvore de Natal, 1920; Teoria da Indiferença, 1920; Leviana, 1921; Nós, 1921; Colette, Colette Willy, Colette, 1921; Gabriele D'Annunzio e Eu, 1922; A Idade do Jazz-Band, 1923; Mar Alto, 1924; A Amadora dos Fenômenos, 1925; Viagem à Volta das Ditaduras, 1927; Praça da Concórdia, 1929; Novo Mundo, Mundo Novo, 1930; Hollywood, Capital das Imagens, 1931; Salazar, o Homem e a Sua Obra, 1933; Prefácio da República Espanhola, 1933; Homens e Multidões, 1941; D. Manuel II, o Desventurado, 1954 e as póstumas Saudades de Mim, 1957 e Obras de Antônio Ferro, 1987.

Dentre os títulos citados, as únicas obras de poesia são Árvore de Natal (1920) e a póstuma Saudades de Mim (1957) e, destarte, é possivel que o poema "A Catedral" tenha sido publicado em algum desses volumes, já que não temos a informação precisa por serem as obras de Ferro pouco difusas no Brasil. Há ainda a possibilidade de que as obras de 1913 tenham sido perdidas, uma vez que Fernando Pessoa na obra Páginas Íntimas e de Auto-Interpretação (1966, p.55), comenta algumas obras de Ferro do citado ano mas que, no entanto, não foram posteriormente encontradas pelos pesquisadores de Antônio Ferro e não se tem notícia de que tenham sido publicadas. 
Notamos portanto que a revista $O$ Ocidente, apesar de se encaixar numa linha de imprensa mais tradicional e estreitamente ligada ainda aos modelos de ilustrações do século anterior, não deixou, contudo, de abrir as portas ao contemporâneo, ao moderno e de dar espaço aos novos nomes das letras portuguesas, como pudemos perceber. Sendo uma revista sobretudo de cultura, desempenhou com primazia o papel de difusor de ideias consolidando, assim, juntamente com seus pares, a importância da imprensa periódica na literatura/sociedade portuguesas e, certamente, abriu sendas para que publicações posteriores como Orpheu tivessem o relevo que tiveram nas letras lusitanas.

\section{Referências bibliográficas:}

COBEIRA, Antônio. "Crônica Ocidental.” O Ocidente: Revista Ilustrada de Portugal e do Estrangeiro. Lisboa, volume XXXVI, número 1259, p.1 e 2, 20 dez. 1913. FERRO, Antônio. "A catedral." O Ocidente: Revista Ilustrada de Portugal e do Estrangeiro. Lisboa, volume XXXVII, número 1264, p.4, 10 fev. 1914.

GALHOZ, Maria Aliete. Mário de Sá-Carneiro. Lisboa: Ed. Presença, 1963.

LISBOA, Eugênio. (coord.) Dicionário Cronológico de Autores Portugueses. (vol. III). Lisboa: Publicações Europa-América, 1994.

MARTINS, Fernando Cabral. (coord.) Dicionário de Fernando Pessoa e do Modernismo Português. Lisboa: Caminho, 2008.

PESSOA, Fernando.( pref. de George Rudolf Lind e Jacinto do Prado Coelho). Páginas Íntimas e de Auto-Interpretação. Lisboa: Ática, 1966.

PIRES, Daniel. Dicionário das revistas literárias portuguesas do século XX. Lisboa: Contexto, 1986.

SÁ-CARNEIRO, Mário. "Salomé”. O Ocidente: Revista Ilustrada de Portugal e do Estrangeiro. Lisboa, volume XXXVII, número 1261, 10 jan. 1913.

SARAIVA, Arnaldo. O modernismo brasileiro e português: subsidios para o seu estudo e para a história das suas relações. Campinas: UNICAMP, 2004 